\title{
Sergio Guzmán Bondiek: Discurso de homenaje
}

\author{
Dr. OSVALDO LLANOS L. ${ }^{1}$
}

1 Pontificia Universidad Católica, Santiago, Chile.

\section{Tribute to Sergio Guzmán Bondiek}

Señor Presidente y miembros del Directorio de la Sociedad, señores Maestros de la Cirugía presentes, señoras y señores:

Me siento muy honrado de haber sido designado por la Sociedad de Cirujanos de Chile para rendir el homenaje correspondiente a mi muy querido amigo el Doctor Sergio Guzmán Bondiek al ser nombrado Maestro de la Cirugía Chilena, distinción máxima que otorga la Sociedad.

Con frecuencia esta misión se le entrega a un discípulo cercano al maestro, pero en esta ocasión, quizás, por algunas razones, el directorio prefirió que la realizara un par. Una razón podría ser que no habría sido fácil la elección de la persona si se tiene en cuenta la cantidad de discípulos que con gusto expresarían su reconocimiento al doctor Guzmán, y otra, puede ser que, quizás los 47 años, casi medio siglo, que nos conocemos me podría dar alguna ventaja para hacerlo. Sin embargo, es probable que me lo haga más difícil.

No quisiera hacer un discurso de homenaje tipo, impersonal. Como dijo García Lorca, al rendir un homenaje a un poeta amigo: "No vengo a hacer falsos halagos, protocolares, muchas veces encubridores de otros sentimientos. No vengo yo en este momento como amigo del homenajeado, Sergio Guzmán en este caso, ni como amigo vuestro, ni a ofrecer este banquete para cumplir un rito gastado con discursos decorados. No vengo tampoco dispuesto a que mi voz la lleve el aire para recibir en cambio, como tantas veces, una bandeja de aplausos coronada por un "muy interesante" de merengue". Vengo a saludar con reverencia y entusiasmo a mi amigo Sergio a quien merecidamente, la Sociedad de Cirujanos ha decidido que le llamaremos maestro.

La palabra maestro puede tener variadas acepciones, todas alrededor de la expresión de la excelencia en el quehacer. Desde su significado más simple, que maestro es el que enseña, el profesor, labor para nada sencilla. En Medicina la maestría indica por una parte, la culminación de un proceso de dominio profundo de su disciplina, ciencia y arte, con el agregado de la capacidad de hacer un aporte conceptual a ella, de un pensamiento personal, y por otra, la habilidad de trasmitir sus conocimientos y experiencias a sus discípulos, es decir, la capacidad formadora. En Medicina, el maestro es el que ejerce su profesión con alegría, con conocimiento, con habilidad, con prudencia, en último término o en una palabra con sabiduría. Para ser médico verdadero se necesita sabiduría. Como dijo Paracelso, hay dos especies de conocimiento, el conocimiento científico y la sabiduría médica. Sabiduría es ver las cosas como Dios las ve y vivir de acuerdo a ello.

El doctor Sergio Guzmán Bondiek nació en Santiago, el 11 de Noviembre de 1942. Hijo de distinguidos médicos. Su padre, el doctor Leonardo Guzmán Cortés, prestigioso cirujano, pionero de la cancerología en Chile, hombre público, diputado, senador, ministro de estado, de muy importante legado para el desarrollo de la Medicina Nacional. También fue Presidente de la Sociedad de Cirugía de Chile, predecesora de la Sociedad de Cirujanos de Chile, podría decirse como un vaticinio del futuro que uno de sus hijos también ocuparía la presidencia de la Sociedad. Su madre, la doctora Erika Bondiek, de nacionalidad alemana, distinguida psiquiatra, quien ejerció su especialidad en forma destacada en nuestro país. El ejemplo de sus padres se reflejó en que los dos hermanos, no sólo fueron médicos, sino que ambos han sido muy distinguidos especialistas, ambos profesores universitarios, uno, Leonardo, en la Universidad de Chile y el otro, Sergio, en la Universidad Católica.

Sergio estudió en el Colegio Saint George de Santiago, el antiguo, de Pedro de Valdivia con 
Pocuro, donde además de recibir la formación cristiana y social de la Holy Cross, hizo de buenos amigos que mantiene hasta hoy.

En 1961 ingresó a la Escuela de Medicina de la Universidad Católica. Sus compañeros lo recuerdan como un muy buen alumno, no preocupado por las notas, ni por los primeros puestos, siempre alegre y relajado, muy buen amigo. Se recibió de médico cirujano en 1968. Hizo su formación quirúrgica primero en la misma universidad con una beca primaria de Cirugía General de 1968 a 1971, bajo la jefatura del Profesor don Hugo Salvestrini. Junto con adquirir los conocimientos y destrezas iniciales como cirujano, recibió allí la impronta de varios docentes, verdaderos maestros formadores tanto en el aspecto técnico como humano.

En Junio de 1968, hace 40 años, contrajo matrimonio con Elena Karadima Fariña, Lula, aquí presente, con quien formó una hermosa familia. Cuatro hijos y 9 nietos. Sus hijos, Sergio, médico, cirujano urólogo, Macarena, ingeniera agrónoma, regalona, Rodrigo, abogado y Gonzalo, sacerdote, linda variedad.

Respetuoso de sus compromisos universitarios y sociales, cumplió con su destino de postbeca en la ciudad de Talca. Era el sistema de integración docente asistencial vigente en esa época, que cumplía bien con sus objetivos, tanto para los médicos en especialización, que obligaba a los becados primarios a una estadía en provincia de al menos 2 años, como para los enfermos de la zona, que así tenían acceso a una mejor medicina.

Allí trabajó duro 2 años, 1971 a 1973, practicando la cirugía general, es decir, cirugía digestiva, torácica, vascular, cuello, mama, etc, de acuerdo a las necesidades de la zona, para luego centrarse en la cirugía digestiva, formando el primer equipo de esta disciplina en ese hospital. Años en que si bien fueron de trabajo intenso, el entorno permitía fortalecer la vida familiar y establecer lazos de amistad con otros exbecarios de distintas especialidades y con otras personas de la zona.

Luego regresó a Santiago, a la Facultad de Medicina de la Pontificia Universidad Católica, primero en el Hospital Sótero del Río, hospital asociado a la Facultad, vinculado preferentemente a la docencia, con una tremenda actividad operatoria de ese hospital, que contribuyó ciertamente a su perfeccionamiento clínico y quirúrgico. En esa época, de difícil supervivencia para un profesional joven en nuestro país, complementó su trabajo con un turno de urgencia en el Hospital de la Fuerza Aérea, de gratos recuerdos para él y para quienes allí lo aquilataron.

Por sus méritos y por sus características personales, de futuro desarrollo académico, se trasladó al Hospital Clínico de la Universidad Católica en 1975, donde prosiguió hasta ahora su desarrollo profesional. En ese tiempo, aparte de su actividad quirúrgica, se hizo cargo también de la endoscopía digestiva del Hospital, disciplina que siempre despertó gran atractivo para él.

El cirujano -el buen cirujano- es a la vez un artista, un artesano, un tecnócrata y un científico. Para ser un buen cirujano, se requiere de algunas cualidades especiales como creatividad, disciplina, serenidad, juicio y pensamiento crítico; además de los conocimientos y destrezas propios de la especialidad. Creo que muchas de las cualidades del cirujano se van revelando o haciendo presente en forma progresiva a lo largo de su vida, como lo fue demostrando el doctor Guzmán en su destacada trayectoria.

En 1975, impulsado por su necesidad de aprender, viajó a Japón, becado por la JICA, al Seminario de Cáncer Gástrico, de mucha utilidad para su vida futura, no tan sólo por los conocimientos adquiridos, sino que también por la disciplina de trabajo que caracteriza a la cultura oriental. Rápidamente incorporó sus nuevos conocimientos, habilidades endoscópicas y quirúrgicas a la práctica en nuestro Hospital.

Prosiguió su senda de perfeccionamiento y fue becado dos años, 1977-1979, en el Departamento de Cirugía de la Universidad de Texas en Galveston, Texas, bajo la tutoría de su jefe el profesor James C. Thompson, también de marcadora influencia en el desarrollo científico, académico y personal del doctor Guzmán. La rigurosidad de la metodología de la investigación, en el trabajo clínico y quirúrgico inculcada en su estadía en este centro académico de alto nivel fueron influencias que encontraron terreno fértil en la inquietud científica de Sergio.

La esencia del maestro radica en un compromiso personal, en la actualización permanente y en la estricta profesionalización, para la búsqueda de la verdad. Esto significa no sólo estar al día en la profesión, sino también estar consciente de los cambios sociales, económicos, políticos y culturales y de las transformaciones que ha vivido la sociedad y de la responsabilidad que ello implica.

El doctor Guzmán realizó luego varias visitas de perfeccionamiento a otros centros de Europa y Norteamérica como también ha sido profesor invitado a dar charlas y participar en actividades científicas en distintas universidades. Puede destacarse su estadía en Alemania para perfeccionar su entrenamiento en cirugía endoscópica con el Profesor Manegold, su intercambio permanente con otros centros universitarios europeos, alemanes en especial, entre los que puedo destacar Munchen, donde labró una genuina amistad con su jefe el Profe- 
sor Siewert, entre otras, y un activo intercambio académico con profesores de otras latitudes. Debo decir que, probablemente por sus genes maternos, Sergio siempre ha tenido una gran admiración por la cultura alemana y la seriedad y estrictez de su trabajo es una muestra de ello.

En la Universidad, Sergio se ha destacado por su dedicación desinteresada al trabajo académico. Gran docente del día a día, en la enseñanza tutorial que caracteriza a la formación quirúrgica. En esta actividad, como ustedes saben no basta con transmitir una técnica quirúrgica, sino que es muy importante el criterio clínico que indica cuando y como proceder, y cuando no intervenir. En este aspecto además de la formación de numerosas generaciones de cirujanos, los demás miembros del departamento sin duda que nos hemos beneficiado de sus enseñanzas. Muchas veces hemos sentido la seguridad de su mano amiga en una intervención difícil o el consejo invaluable en el tratamiento de un enfermo complejo. En su interés particular y en investigación dentro de la cirugía digestiva ha sabido encausar su mayor esfuerzo en aspectos como el cáncer gástrico, la antigua úlcera péptica, la cirugía hepática, biliar y pancreática, la fisiopatología de las enfermedades digestivas, con múltiples publicaciones en Chile y en el extranjero. Fue pionero e iniciador del programa de trasplante de hígado en la Universidad Católica, programa que ya está en otra etapa de desarrollo y ha superado los 100 pacientes trasplantados. Pionero en la cirugía endoscópica, fue de los primeros en realizar la papilotomía endoscópica en nuestro país, también pionero en la cirugía laparoscópica y luego manifestó su liderazgo en la cirugía bariátrica y metabólica. En todos estos temas siempre ha impulsado, con generosidad, a académicos más jóvenes a desarrollarlos, siguiendo el precepto del maestro, que estimula a sus discípulos a superarlo, concepto no siempre bien entendido en nuestro medio. Sus discípulos han entendido el precepto que el mejor tributo que se le puede rendir a las personas buenas es imitarlas. Herbert Spencer, pensador inglés del Siglo XIX afirmó "el objeto de la educación es formar seres aptos para gobernarse a sí mismos y no para ser gobernados por los demás".

En su carrera universitaria, Sergio ha ocupado varios cargos de elevada responsabilidad, ha sido Jefe de Servicio de Cirugía, Jefe de Departamento de Cirugía Digestiva, Jefe de la División de Cirugía, que es la estructura académica principal en nuestra Facultad. Ha sido también miembro del Consejo de Facultad y Director de Graduados de la Escuela de Medicina hace algunos años. Todos estos cargos revelan su desinteresado espíritu de servicio para los demás y para la institución y aunque no lo pa- rezca son ajenos a su manera de pensar respecto a este tipo de posiciones, a las cuales él es más bien esquivo. Participó activamente en la reestructuración académica de la disciplina quirúrgica en la Facultad de Medicina de la Universidad Católica, con lo que se logró un fuerte impulso al desarrollo académico, científico y tecnológico de la Cirugía en los últimos 15-20 años en nuestra institución. Su carrera académica culminó en 1995 al ser nombrado Profesor Titular de la Universidad. La Facultad de Medicina de la Universidad Católica se siente orgullosa de contar entre sus miembros al doctor Sergio Guzmán Bondiek y tengo el encargo de hacerlo presente en este acto.

Ingresó a la Sociedad de Cirujanos en el año 1976 donde también ha tenido una muy destacada trayectoria, participando en todas las actividades societarias, cursos, congresos, editor de libros, numerosas publicaciones, cargos directivos, llegando a ocupar la Presidencia en 1996.

Gran lector, aficionado y conocedor de la música clásica, de la ópera. Siguiendo su predilección germana, Mahler es uno de sus compositores preferidos. Entre su gustos destaca también su capacidad de disfrutar de la naturaleza y en ello se inserta su pasión por la moto, deporte en que es realmente un experto y quizás si no también podríamos llamarlo maestro. Otro de sus deportes favoritos ha sido el ski, que lo aprendió de niño en algunas de sus visitas a Alemania.

Entre otras de las cualidades esenciales que debe tener el cirujano, resalta en el carácter del doctor Guzmán la humildad. Puedo dar fiel testimonio de ello. Nadie puede dudar que así como la cercanía con el sufrimiento y la visión de la muerte y, por otra parte, la alegría y el reconocimiento del éxito , no pueden sino imponer la humildad en el actuar del cirujano. El quehacer médico diario, del cirujano en particular, con éxitos y fracasos, es un llamado permanente a la humildad.

Por todas estas razones, entre otras, por tu entrega demostrada a la noble profesión médica, expresada en la excelencia quirúrgica, expresada en el trato responsable y cariñoso con los enfermos, expresada en la enseñanza de la cirugía a los alumnos y en la formación de discípulos, expresada en una visión universal del hombre, en el desarrollo académico universitario, expresada en el cultivo de la amistad con colegas y compañeros de trabajo, expresada en la dedicación a la Sociedad de Cirujanos que hoy día nos cobija y te distingue con la maestría por tu aporte a la Cirugía chilena, por tu ejemplo de vida, es que nos ponemos de pié para saludarte.

Muchas gracias.

19 noviembre, 2008. 


\section{Agradecimientos del Dr. Sergio Guzmán B.}

Estimados colegas y amigos, señoras y señores:

Reconozco este nombramiento como sorpresivo e inesperado para mí. Esta honrosa distinción tiene el gran valor de que proviene de la Sociedad de Cirujanos de Chile, institución de la que formamos parte cirujanos de todo el país y que tiene por misión encauzar y representar ésta especialidad que todos queremos tanto, lo que le da su particular significado.

Este es entonces un momento adecuado para agradecer y también para que en palabras simples podamos hacer algunas reflexiones y recuerdos y finalmente de nuevo para agradecer. Quiero reiterar mi reconocimiento a la Sociedad a través de su Presidente, de su directorio y de una persona cuya dedicación a la Sociedad ha sido ejemplar a lo largo de los años: me refiero al doctor Antonio Yuri. También agradezco sinceramente al doctor Osvaldo Llanos designado por el directorio para hacer esta semblanza. Nuestras familias han compartido una amistad de toda una vida, desde nuestra época de residentes hasta ahora, con momentos de mucho agrado, también con largas horas en pabellón, con sus satisfacciones y también con sus frustraciones. Quiero decirle a él y a ustedes que en sus palabras veo más cariño que objetividad y también decirle que con gusto habría invertido los roles hoy día. Siento además que ésta distinción no es sólo mía sino que por deber y también por gratitud la comparto con aquellas personas que han hecho posible nuestro trabajo a lo largo ya de cuarenta años.

Al recibir ésta distinción no puedo dejar de pensar también con emoción en mi familia, representada hoy aquí por mi señora Lula y por mis hijos Sergio y Macarena. Creo que sin una familia como la que tuve, sin la compañía y la comprensión de mi señora y sin el estímulo y cariño de mis hijos mucho del trabajo que realizamos en estos años simplemente no habría sido posible. Nuestra larga vida en común adquiere todo su significado el día de hoy.

También creo oportuno recordar a mis padres, ambos médicos. Él nacido en 1890 en Antofagasta, que por generación podría haber sido mi abuelo, fue cirujano, oncólogo y político, combinación que en ese entonces era más posible que ahora; recuerdo su empuje y su entusiasmo por esta profesión (en la que se mantuvo activo hasta el final) y su capacidad inagotable de estudio, para estar siempre al día. Él fue "becado" con Madame Curie y

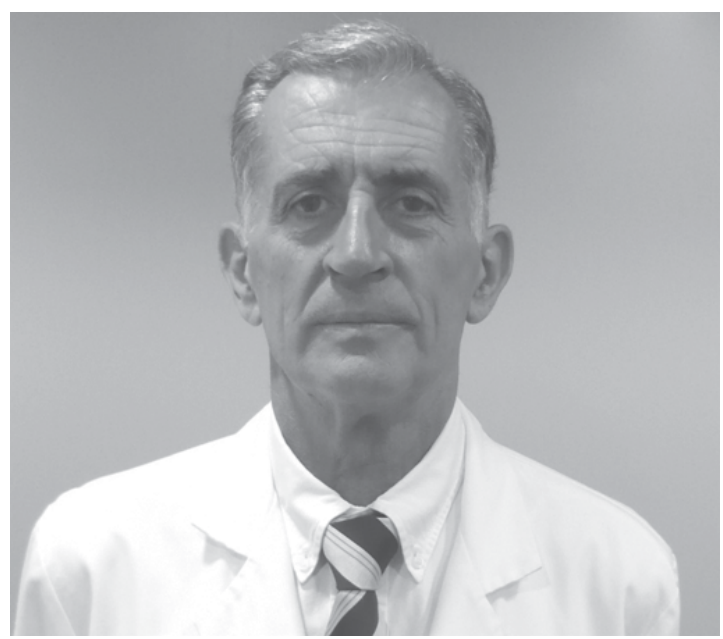

amigo de Ewing, Huggins, Pack y Karnofsky entre otros. Ejerció sus labores docentes en la Universidad de Chile, y fue Presidente de la Sociedad de Cirugía de Chile, que se fundó en 1922 y que fue antecesora de esta Sociedad fundada en 1949, al fusionarse con la Sociedad de Cirujanos de Hospital. En el ejercicio de su trabajo docente conoció a nuestra madre, siquiatra alemana que abandonó su país en 1937 al intuir la catástrofe que se avecinaba en Europa. Ella buscaba revalidar su título, lo que logró sin problemas, desempeñándose posteriormente como siquiatra en la Universidad de Chile, en la cátedra del Profesor Ignacio Matte y luego como sicoanalista, trabajando activamente hasta los 85 años de edad. Su imagen como mujer estudiosa y más bien introvertida es inolvidable para mí. Nuestra casa y familia eran más bien atípicas, con mucha libertad en nuestras decisiones, pero a la vez muy influyente por el ejemplar compromiso que ambos tenían con su profesión y con su trabajo. Esto determinó claramente que mi hermano y yo fuéramos médicos; mi hermano estudió en la Universidad de Chile y yo en la Católica, en cursos paralelos. Nunca olvidaré la satisfacción de nuestro padre al entregarnos el título en 1968. Quiero recalcar que yo al menos jamás recibí presión por parte de ninguno de ellos para estudiar medicina, pero confieso que en ese entonces simplemente no consideré otra alternativa.

En estos momentos no puedo dejar de lado el simple y común pensamiento de la rapidez con que transcurre el tiempo. Los siete años de estudio, los tres de residente y luego los años que trabajamos en Talca, y en el Hospital Sótero del Río, pasaron volando. Cada vez que hago recuerdos me impresiona como ha cambiado y progresado la cirugía y la medicina y también de qué manera tan profunda ha cambiado el ejercicio de esta especialidad. Cuando nos recibimos no existía la ecografía, la 
tomografía computada, y para que mencionar la resonancia nuclear. La endoscopía tampoco se usaba y surgió algunos años después junto con otros recursos como por ejemplo la nutrición parenteral. A manera de recuerdo y para ilustrar este progreso quiero mencionar a Jorge Tocornal, distinguido cirujano de temprana desaparición en 1981. A veces he soñado que él vuelve, luego de una larga enfermedad, y reflexiono que mucho de lo que operamos juntos incluyendo gastrectomías, coledocostomías, derivaciones porto sistémicas ya prácticamente no se hacen. En nuestro diálogo imaginario él reconoce que está teniendo que enfrentarse a una nueva especialidad. No se vislumbraba en ese entonces que la colecistectomía, entre otras muchas operaciones, se haría por vía laparoscópica.

En los últimos años no sólo hemos vivido enormes progresos técnicos sino que también hemos asistido a cambios en la forma en que trabajamos y muchas veces incluso en lo que nos mueve y nos motiva. Frecuentemente hoy predomina la sensación de una especie de competitividad, con objetivos de corto plazo, que van más allá de lo que es conveniente. Esto va de la mano con el uso creciente del llamado marketing, por parte de las instituciones y también a veces por parte de los propios cirujanos. Hoy el paciente y también el alumno son clientes. Sin desacreditar a priori estas tendencias, muy propias del mundo de hoy, quiero recalcar que siempre es bueno volver a los valores básicos que nos enseñaron nuestros maestros y que han caracterizado nuestra profesión y muy en particular a nuestra especialidad: buscar primero el beneficio del paciente. Este beneficio se consigue simplemente aspirando a la excelencia en lo que se hace. La aspiración a la excelencia es eso, es una búsqueda o un anhelo que nos compromete con lo que hacemos y que nos hace humildes porque nos recuerda permanentemente que siempre hay espacio para mejorar. La cirugía tiene el gran desafío de la excelencia en lo técnico, es decir ser capaz de hacer bien una operación, sin someter al paciente a riesgos que no corresponden. Este, que es un gran atractivo para nosotros, sin embargo, no es el único y tampoco es suficiente. No basta con ser buen operador, también es necesario aspirar a la excelencia en lo científico, lo que significa mantenerse en la actualidad del saber y también en lo posible participar en la generación de nuevos conocimientos y saber aplicarlos en forma oportuna, de nuevo, para beneficio del paciente. Considerando la velocidad con que se renuevan los conocimientos hoy en día ésta tampoco es una meta simple y por si fuera poco en nuestra especialidad tampoco es suficiente. Es necesario además aspirar a la excelencia en nuestro trato con el paciente, con su familia, con otros colegas. Hay que aprender a ganarse la confianza de otro ser humano que se entrega para ser invadido por nosotros. Hay que saber mante- ner la objetividad y la verdad en lo se pretende hacer, en lo que se hace, y en lo que se informa. El acto quirúrgico debe tomarse como un acto de compromiso personal con el paciente y no un mero trámite rutinario. Por último, y quizás en primer lugar hay que buscar la excelencia en nuestros objetivos personales, es decir aquellos que inspiran en lo profundo lo que hacemos. Hoy día se nos ofrecen como objetivos legítimos el bienestar económico, la categoría social, incluso el rango académico. Siendo estos fines parte integrante de la vida, no hay que olvidarse que el fin último debe ser simplemente de servir y de servir bien.

He tenido la suerte de desempeñarme profesionalmente durante muchos años en una institución académica a la que guardo profundo cariño y donde conocí a destacados maestros y amigos. No puedo nombrarlos a todos. Ya mencioné al doctor Jorge Tocornal; de él, del doctor Hugo Salvestrini, del doctor Arnaldo Marsano y de muchos otros reconozco lo mucho que he recibido y he aprendido a lo largo de estos años. También reconozco como fundamental la posibilidad de ampliar horizontes en el extranjero. El mundo de hoy ha hecho de esto algo expedito, casi rutinario. Para mí, sin embargo, mi estadía en el Cancer Institute de Tokio y mis años de trabajo en Estados Unidos bajo la jefatura del doctor Thompson, posterior presidente del ACS fueron oportunidades de apertura cultural y científica de influencia permanente en mi vida profesional. También lo han sido otros vínculos de amistad y trabajo en Europa que complementan hasta hoy mi formación, como por ejemplo con Rudiger Siewert y Jens Witte, ambos, miembros honorarios de esta Sociedad. Por otra parte, no hay duda que el ambiente universitario es ventajoso porque no hay nada que enseñe más que la labor docente. El intercambio con alumnos, con residentes, y con otros docentes es tremendamente enriquecedor y estimulante, así como lo es la posibilidad de complementarse con otros especialistas. Este estímulo no es exclusivo del ambiente universitario pero si forma parte de su esencia. La labor académica va también de la mano por definición y de manera inseparable con la búsqueda de una organización que facilite la generación de los conocimientos y que deje espacio para su mejor trasmisión. Ni las estructuras, ni la organización sustituyen la calidad individual, pero sin duda contribuyen al crecimiento $\mathrm{y}$ al desarrollo. Pensando en nuestra especialidad, considero oportuno trasmitir la experiencia que vivimos en mi universidad. En 1974, se realizó una reorganización estructural, que llevó a la departamentalización de la Facultad con el fin de favorecer el desarrollo de las distintas especialidades. Lamentablemente en esa oportunidad no se creó un Departamento de Cirugía, quedando los cirujanos incorporados en los distintos Departamentos Médico-quirúrgicos. Por paradoja, seguía existiendo el 
alumno de cirugía, el becado de cirugía, el examen de cirugía y el profesor de cirugía, pero sin instancia académica que aglutinara e impulsara todos estos intereses comunes de los cirujanos. El tiempo demostró, a mi entender inequívocamente, que ésta decisión si bien tenía su fundamento no fue la mejor. Conseguir el consenso académico para revertirla tomó veinte años, hasta llegar a la creación de la actual División de Cirugía, que incluye a los distintos Departamentos Quirúrgicos. La creación de esta nueva estructura permitió alinear a los cirujanos en sus intereses comunes y en los de la Facultad, y ha demostrado en mi opinión en forma clara su beneficio y su operatividad. Las características propias del trabajo quirúrgico determinan que aún cuando los cirujanos se desempeñen en especialidades y subespecialidades aparentemente tan diferentes, sus vínculos de unión se hacen evidentes y adquieren fuerza en forma casi espontánea. Esta unidad debe mantenerse y cultivarse, tomando los resguardos necesarios para cautelar la identidad de la disciplina quirúrgica, reconociendo su raíz común. Sin embargo, es necesario reconocer también la trascendental importancia del trabajo multidisciplinario para el progreso médico quirúrgico y para que complementando conocimientos podamos atender mejor a nuestros pacientes. Esto se logra juntando a los distintos especialistas en torno a áreas de interés común, como por ejemplo los programas de obesidad, o de trasplante o las unidades dedicadas en forma multidisciplinaria a campos más específicos de la patología como podría ser la unidad de patología inflamatoria intestinal. La estructura académica unitaria, por una parte, complementada con la formación de grupos o programas de trabajo multidisciplinarios, ha otorgado la flexibilidad y la agilidad necesarias para el trabajo médico de hoy en nuestra institución creo yo que haciendo auspicioso el porvenir.

Sin embargo, aparte de la excelencia como objetivo central y de la mejor organización y estructura que uno pueda darse, hay que tener presente que la cirugía por definición no es el trabajo de un cirujano solo. Esta especialidad es esencialmente un trabajo de equipo, pensando esta vez en el equipo de cirujanos que comparten una especialidad. La formación de un buen grupo quirúrgico pasa por dar espacio a otros cirujanos que trabajan con uno, pasa por compartir éxitos y dificultades, pasa también por saber combinar lo establecido con aquello que representa una innovación. También es necesario dejar espacio para que los integrantes más jóvenes de un equipo quirúrgico tengan lugar para desarrollar plenamente sus potencialidades, combinando su ímpetu con la experiencia de los mayores. Incluso, en la medida de lo posible, la creación de grupos pasa por la capacidad de distribuir trabajo y también ingresos. De esta manera mientras un integrante del equipo realiza una labor docente y otro atiende policlínico hay un tercero que puede estar operando un paciente privado, todos para beneficio de todos. Un grupo de trabajo se forma, dicho de otra manera, no con el objetivo principal de distribuir ingresos sino que centralmente para distribuir el trabajo y compartir con reglas claras sus beneficios. Esta ha sido otra característica central de nuestra vida quirúrgica y quiero ahora decir que ha sido para mi un tremendo privilegio tener la certeza que he sido y sigo siendo parte de un equipo. Ha sido un privilegio formar equipo con colegas como el doctor Osvaldo Llanos, Álvaro Zúñiga, Alejandro Raddatz, Alejandro Rahmer, Luis Ibáñez, Fernando Pimentel, y ahora con un destacado y estimulante grupo de cirujanos más jóvenes como el doctor Nicolás Jarufe, Jorge Martínez, George Pinedo, Gustavo Pérez, Juan Francisco Guerra, la doctora María Elena Molina, el doctor Alex Escalona y el doctor Fernando Crovari, Camilo Boza, Alan Sharp, Ricardo Funke y Felipe Bellolio. A ellos les confieso mi sana envidia por sus capacidades y por su juventud. De su altura de miras y de la complementación de sus destrezas depende la solidez de su futuro.

Finalmente hay otras personas a quienes quiero agradecer. Al equipo de cirujanos que comparten el interés por una especialidad, a los múltiples especialistas que juntan sus esfuerzos por el bien de los pacientes, hay que reconocer y agradecer la ayuda frecuentemente silenciosa, modesta y abnegada de otros profesionales que integran nuestro equipo, complementando nuestro trabajo y especialmente de quienes trabajan en pabellón. Pienso en el personal auxiliar, en las enfermeras, y en quienes nos arsenalean. Como dije este es un trabajo silencioso pero básico, fundamental, sin el cual nada de lo que hacemos sería posible. En particular, quiero agradecer a Francisca Acevedo su abnegado trabajo de años conmigo como arsenalera en pabellón, en cientos de procedimientos quirúrgicos, con total dedicación y sin límite de horarios. Con todas las personas con que trabajamos en pabellón compartimos esos momentos tan propios de la vida quirúrgica que pueden ser de gran satisfacción frente a un procedimiento exitoso como también de angustia o profundo pesar como ocurre a veces al constatar una enfermedad incurable o al hacer frente a un procedimiento difícil o a una complicación inesperada. En el pabellón pienso, nos revelamos realmente como somos. Ojalá podamos hacer del respeto mutuo una manifestación permanente en nuestro trabajo.

Todo esto hace de esta especialidad algo único. Quiero aprovechar este momento tan especial en mi vida para dar gracias a Dios por haber podido contribuir al servicio de otros como cirujano y por poder compartir esta tarde con ustedes.

Muchas gracias 